\title{
USE OF THE NATIONAL GRID
}

SIR, - The reference to the new ordnance maps in the May-June number of the Geological Magazine prompts me to venture to suggest to geologists engaged in field mapping in this country that the fullest possible use should be made of the national grid. Speedy and certain identification of exposures described in geological literature is important both to the research worker who may wish to re-examine the evidence on the ground, and to the student who is endeavouring to make himself acquainted with representative sections, and furthermore is a convenience to the geologist who, without being seriously concerned with details, nevertheless wishes to obtain a general idea of the structure or stratigraphy of an area which he may be visiting. Yet it is all too common to find that descriptions of localities are based on some feature that is not shown on the present one-inch map, and which is perhaps no longer in existence. An old quarry or barn may have been well known at the time the mapping was done, but after 20 or 30 years changes may have taken place that make it impossible to recognize the reference point; a stream, lane, or farm may be named on the six-inch map but not on the one-inch, and it is not always practicable to consult the six-inch map, whilst local inquires may waste much time, with no certainty of success. Merely by the use of the one-inch gridded map a reference can be given to the nearest 80 yards, and the new $1: 25,000$ maps give greater precision with equal ease.

Related to this plea for the use of the national grid is another for adequate and accurate topographical detail in large-scale maps. I recently wished to use a two-inch geological map illustrating a paper ; topography was limited to the larger streams - there were no roads, villages, etc. It seemed that it might be convenient to add the national grid for ready comparison with both the one-inch and $1: 25,000$ maps. A photographic copy made on the 25,000 scale was compared with the ordnance map, but the streams were so generalized that an exact " local" fit was often not possible even on a tracing table, whilst the inaccuracies were sufficient to preclude a satisfactory " general " fit which would enable the grid to be made use of. Another map on the same scale had a few widely-spaced contours, but even then could not be accurately fitted either locally or generally to the ordnance map.

In a third instance a map which, being of an open character, had ample room for topographical detail, had, besides the geological lines, a few stream courses and village churches but no roads. It was accordingly difficult to locate boundaries. The map happened to be on one of the published scales of the ordnance survey, and I supposed that it would be easy to transfer the geology to the ordnance map by simply 
tracing it through. I found that although there was usually a good local fit on the few streams shown, it was not possible to get a satisfactory general fit, and consequently in areas away from the streams there was some uncertainty about the positions of boundaries.

I have also noticed instances of maps which lack a graphic scale and are incorrectly stated to be so many inches to a mile; this was the scale of the original which was reduced when the block was made, and there is no direct indication of the scale of the printed map, which has to be worked out by comparison with an ordnance map.

These have all come to my notice within the past few months, although the maps themselves range over many years. In every case much, if not all, of the difficulty of using them would have disappeared had there been a national grid in existence and had it been accurately incorporated in the original map.

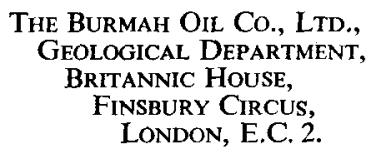

P. Evans.

\section{YOUNGER TECTONICS AND EROSION IN WESTERN AUSTRALIA}

SiR,--In a recent discussion in this Magazine, which has only now come to hand, ${ }^{1} \mathrm{C}$. A. Cotton postulates that the tempo of denudation in Western Australia during the Pliocene and Pleistocene could not possibly have been rapid enough to allow the levelling down of a strong relief newly created by folding and faulting of late Miocene or Pliocene age. He suggests that the tectonic movements in the North-West Basin to which I have ascribed such an age must have taken place rather earlier, though he does not say when. He finds support for these conclusions in certain features of the geology of Victoria and New South Wales.

Unfortunately, however, these theoretical deductions are contradicted by field evidence, and I also fail to see the relevance of geological observations in south-eastern Australia for the interpretation of the geological history of remote parts of Western Australia. Incidentally, the south-east corner of Australia is a good deal nearer to New Zealand than to the North-West Basin of Western Australia. Professor Cotton has opened a discussion on a most interesting subject and I regret more than ever that I found it impossible to deal more fully with the

${ }^{1}$ C. A. Cotton, Query as to the Tempo of Denudation in Australia. Geol. Mag., lxxxv, 1948, 54-6. 